\title{
Evaluation of the Properties of Iron Oxide-Filled Castor Oil Polyurethane
}

\author{
Eleonora Mussatti, , Claudia Merlini, Guilherme Mariz de Oliveira Barra ${ }^{\mathrm{a}}$, \\ Saulo Güths ${ }^{\mathrm{a}}$, Antonio Pedro Novaes de Oliveira ${ }^{\mathrm{a} *}$, Cristina Siligardi ${ }^{\mathrm{b}}$ \\ a Department of Mechanical Engineering - EMC, Federal University of Santa Catarina - UFSC, \\ Campus Universitário, Trindade, CEP 88040-900, Florianópolis, SC, Brazil \\ ${ }^{\mathrm{b}}$ Department of Materials and Environmental Engineering - DIMA, \\ University of Modena and Reggio Emilia - UNIMORE, \\ Via Vignolese, 905, 41100, Modena, MO, Italy
}

Received: April 13, 2012; Revised: July 19, 2012

\begin{abstract}
The aim of this study was to obtain and evaluate the electrical, thermal and mechanical properties of iron oxide-filled castor oil polyurethane $\left(\mathrm{PU} / \mathrm{Fe}_{2} \mathrm{O}_{3}\right)$. The iron oxide used in this study was a residue derived from the steel pickling process of a Brazilian steel rolling industry. Polymeric composites with different iron oxide volume fractions $(2.5,5.0,7.5,10.0$ and $12.5 \%)$ were prepared through the casting process followed by compression molding at room temperature. The composites were analyzed by FTIR, XRD and densities, tensile strength, Young's modulus, electrical and thermal conductivities measurements. By increasing the iron oxide content, the apparent density, tensile strength, Young's modulus and electrical conductivity values of the composites were also increased. The iron oxide additions did not change significantly the value of thermal conductivity (from $0.191 \mathrm{~W} \cdot \mathrm{mK}^{-1}$ for PU up to $0.340 \mathrm{~W} \cdot \mathrm{mK}^{-1}$ for PU enriched with $12.5 \% \mathrm{v} / \mathrm{v}$ of iron oxide). Thus, even at the higher iron oxide concentration, the compounds as well as the pure polyurethane can be classified as thermal insulators.
\end{abstract}

Keywords: polymers, polyurethane, castor oil, iron oxide, wastes

\section{Introduction}

It is unavoidable that during transformation of natural resources in finished products some amounts of solids, gaseous or liquids residues are transferred to the air, water, soil and underground which constitute the big natural containers of our planet. Consequently, as defined by law in most countries, environmental impacts are expected and they may assume particular characteristics which may change, temporarily or permanently, the environment. Such changes may constitute a risk to humans and can become an injury to health.

Thus, it is important to focus the research looking for new production systems, aiming to reduce the consumptions, to use efficiently the potential of the employed materials by recycling those that nowadays are considered wastes in order to create consumer goods in the market that are environmentally friendly and biodegradable when it is possible.

The natural oils are considered one of the most important classes of renewable resources and the use of polyurethane from castor oil is the demonstration of a good example of material generated from a renewable source ${ }^{1,2}$. Vegetable oils are abundant raw materials and most are not toxic, generating little waste during production and they are still characterized by a low cost of production and processing and are biodegradable. Moreover, its use contributes to the

*e-mail: pedronovaes@emc.ufsc.br conservation of global oil reserves. These characteristics yield the vegetable oils interesting products for use as raw materials in chemical industry. In fact, these oils constituted of triglycerides and fatty oils provide a suitable base for the synthesis of polymeric materials ${ }^{2}$. Polyurethanes are versatile materials since they show good workability and can be easily produced. For this reason, they have a wide range of applications, such as in construction, the automotive industry, and the electrical, electronics and footwear production ${ }^{3}$.

According to the formulation and type of load used, the obtained polymeric materials have different characteristics. The benefits obtained by the addition of multiple loads to polyurethanes are, among others, the resistance to extreme temperatures, resistance to corrosion and degradation. These properties may help to reduce the cost of production of the obtained polymeric materials. Moreover, the life time of the product itself can be increased.

On the other hand, the combination of properties of organic and inorganic components forming a single material have attracted interest from researchers, since the polymeric matrix have good processability and flexibilities and the inorganic particles can provide mechanical strength and thermal stability ${ }^{4}$.

Hematite $\left(\alpha-\mathrm{Fe}_{2} \mathrm{O}_{3}\right)$, which is stable under ambient conditions with semiconducting properties, low cost and high resistance to corrosion, has been extensively used for 
the production of gas sensors, catalysts, pigments, magnetic recording media, anti-corrosive agents, and lithium ion batteries with great scientific and technical importance ${ }^{5-7}$. In fact, hematite wastes from rolling steel industries has been used as pigment as reported in the literature ${ }^{8}$ among other typical loads for polymeric materials, such as calcium carbonate, silica, and alumina. Moreover, according to the Siderurgical Brazilian Institute ${ }^{9}$, for each steel tonnage produced (in 2010), $640 \mathrm{~kg}$ of residue is generated, which represents an important amount of waste generate each year, considering that just $15 \%$ of this total is reused.

Thus, it is interesting to inquire about the possibility to use iron oxide waste as loading, in order to obtain new materials that retain almost invariable their physical, chemical and mechanical characteristics in comparison with traditional materials.

In this context, this work report results related to the production and characterization of composites produced with polyurethane derived from castor oil and different volumetric fractions of iron oxide residue, from the steel rolling industry. The mechanical, electrical and thermal properties of the composites were evaluated, in order to obtain polymeric materials for a specific application at low costs.

\section{Material and Methods}

\subsection{Materials}

The polyol derived from castor oil and the pre-polymer were supplied by the company IMPERVEG ${ }^{\circledR}$ Comércio e Prestações de Serviço Ltda. The polyol was synthesized from castor oil, trifunctional polyester, with molar mass of 928 g.mol ${ }^{-1}$. The prepolymer was synthesized by reacting diphenylmethane diisocyanate (MDI) with the castor oil polyol. A percentage of the free isocyanate remained for subsequent reaction. The resin used (IMPERVEG ${ }^{\circledR}$ UG 132 A) for the preparation of the materials was supplied as two components, which were mixed in the mass proportion of 1:2 (one part of the prepolymer and two parts of polyol). Additional details about the synthesis of the polyol and castor oil can be obtained from Merlini et al. ${ }^{10}$. The particulate iron oxide waste with a typical red-brown color and derived from the steel pickling process was provided by a Brazilian steel rolling industry.

\subsection{Methods}

The polyurethane (PU) was prepared by mixing the pre-polymer and the polyol derived from castor oil in bulk as suggested by the manufacturer. The two components were introduced into a reactor, sealed and connected to a mechanical stirrer so that the mixture was stirred for 5 minutes at $130 \mathrm{rpm}$ under vacuum and then poured into a mold. The polymerization was carried out at room temperature for 6 hours, time during which the material hardened and rapidly increased its viscosity. After 2 hours of polymerization a pressure of approximately $10 \mathrm{MPa}$ was applied during 1 hour in order to eliminate further air bubbles.
The particulate iron oxide-added castor oil polyurethane materials were prepared by mixing, in the first place, the components of the PU, as mentioned before. Subsequently, the iron oxide residue (powder) was added (2.5, 5.0, 7.5, 10.0 and $12.5 \% \mathrm{v} / \mathrm{v}$ ) to the PU and mixed for 5 minutes. The formulated mixtures thus obtained were poured in a metal plate $(120 \times 120 \times 2 \mathrm{~mm})$ and formed through hand lay-up process. After 2 hours of polymerization a pressure of approximately $10 \mathrm{MPa}$ was applied during 1 hour in order to eliminate further air bubbles. After curing process at room temperature the material was removed from the mold.

\subsection{Characterization}

The mean particle size of the iron oxide powder $(0.73 \pm 0.12 \mu \mathrm{m})$ was determined by using a laser scattering particle size analyzer (Cilas 1064L particle size analyzer).

Hematite $\left(\mathrm{Fe}_{2} \mathrm{O}_{3}\right)$ is predictably the remaining stable component according to X-ray diffraction, XRD (Model PW 1830, Philips) measured with nickel-filtered $\mathrm{CuK} \alpha$ radiation in the $2 \theta$ range $\left(10-70^{\circ}\right)$.

The average chemical composition of the as-received iron oxide was obtained using quantitative X-ray fluorescence, XRF (Model PW 2400, Philips).

The apparent density $\left(\rho_{\mathrm{ap}}\right)$ of the obtained materials (PU + iron oxide residue) was measured geometrically. The theoretical density $\left(\rho_{t}\right)$ of the iron oxide residue was measured by He-picnometry (AccuPyc 1330, Micromeritics, Norcross, GA; 5 measurements).

Tensile strength $\left(\sigma_{t}\right)$ of samples was performed in an EMIC testing machine (Model DL 2000) on five samples (for each composition) with dimensions defined according to ASTM D638-08 ${ }^{11}$ and ASTM D3039M - $08^{12}$ at a load rate of $5 \mathrm{~mm} / \mathrm{min}$.

The electrical behavior of the produced materials was measured according to the ASTM (D257-99) ${ }^{13,14}$. For the iron oxide the two point method was used with aid of an Electrometer Keithley (Model 6517A/High Resistance Meter with a Keithley electricity source, model 6220). In this case, a sample (a disc with a nominal diameter of $22.0 \mathrm{~mm}$ and thickness of $0.30 \mathrm{~mm}$ ) was prepared by compacting the iron oxide powder in a steel die by using a manual press at $\sim 5 \mathrm{MPa}$ during 1 minute and then for another minute at a pressure of $\sim 17 \mathrm{MPa}$. The specimen was then placed between two electrodes connected to a voltmeter and a source of electricity.

The thermal conductivity was measured in an apparatus based in the use of heat fluxmeter (HFM) built in our laboratories. This HFM, called tangential gradient, is based on the modification of the lines of heat flux to generate a temperature difference in a plane tangential to the plane of measurement ${ }^{15,16}$. The deviation of the flux lines is caused by a copper pin shown in Figure 1. The temperature differences are measured by the deposited thermocouples (cooper over constantan) connected in series. Each thermocouple converts a temperature difference in Seebeck emf. The emf produced is directly proportional to the number of thermoelements distributed on the surface of the sensor. This technique allows the manufacturing of thermocouples without welds, which facilitates the fabrication of transducers with large area of measurement, high sensitivity and reduced thickness. Each HFM is calibrated using a constantan skin heater supplied by a constant power. 


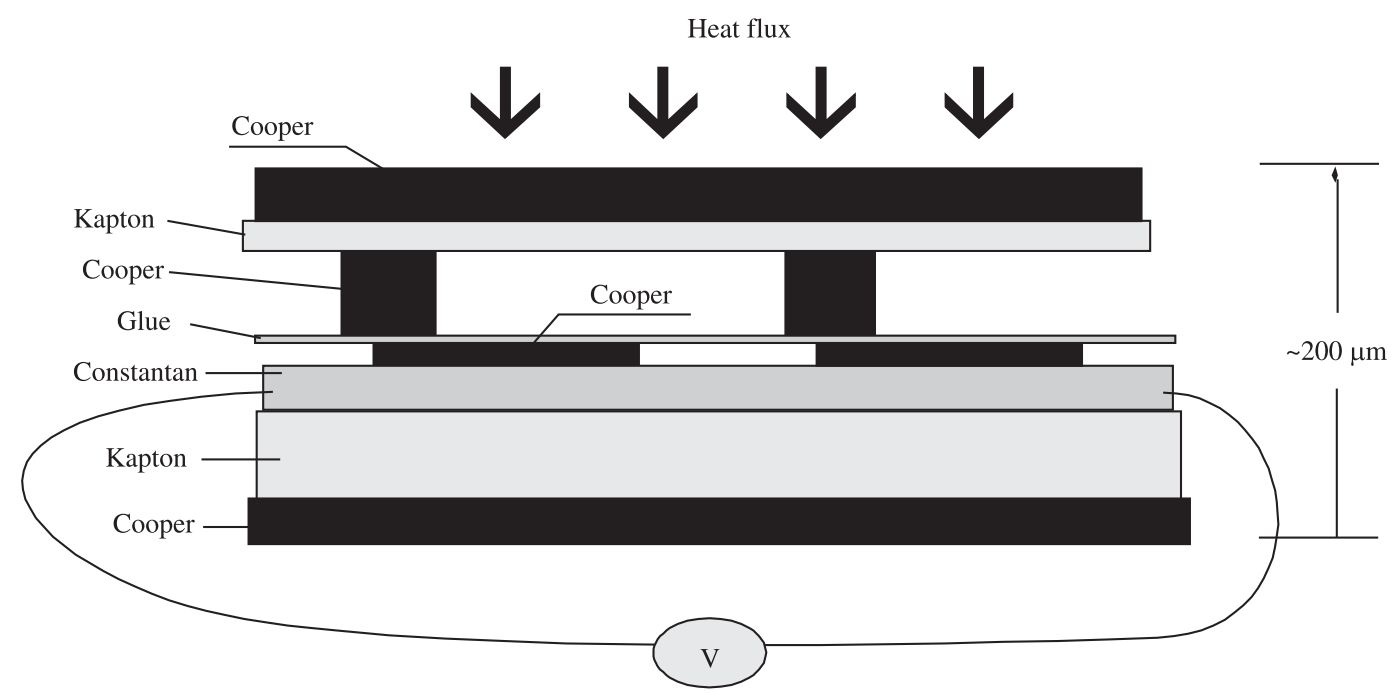

Figure 1. The tangential gradient heat fluxmeter.

The apparatus built to measure the thermal conductivity is based o standards ISO $8301^{17}$ and ASTM C518 ${ }^{18}$ as shown in Figure 2. The sample, with dimension $30 \times 50 \mathrm{~mm}$, thickness $8 \mathrm{~mm}$, is crossing by a heat flux generated by a skin heater in constantan, thickness $50 \mu \mathrm{m}$. The heat flux crossing the sample is measured by two tangential heat fluxmeter, thickness $200 \mu \mathrm{m}$ and sensitive around $30 \mu \mathrm{V}$. $\left(\mathrm{W} \cdot \mathrm{m}^{-2}\right)^{-1}$. The heat fluxmeter has the same surface area of the sample $(30 \times 50 \mathrm{~mm})$. The temperature difference is measured by two Type T thermocouples (AWG 36) placed into the heat fluxmeters. The bottom surface is maintained at a constant temperature, using an aluminum plate with internal circulation of water at controlled temperature $\left(20{ }^{\circ} \mathrm{C}\right)$. The skin heater is supplied by a constant power $(10 \mathrm{~W})$, producing a temperature difference between the faces of the sample of about $15{ }^{\circ} \mathrm{C}$. After 1 hour the steady state is reached, obtaining the value of thermal conductivity through the Fourier's Law. The uncertainty of measurement is estimated to be $4 \%$.

Attenuated Total Reflectance-Fourier Transform Infrared spectroscopy (ATR-FTIR) was performed in a Bruker spectrometer, model TENSOR 27 in the range of 4000 to $600 \mathrm{~cm}^{-1}$ by accumulating 32 scans at a resolution of $4 \mathrm{~cm}^{-1}$, to obtain spectra for polyurethane and composites.

\section{Results and Discussion}

The Table 1 shows the chemical composition of the iron oxide residue (waste) used in this work. As it can be seen from Table 1, iron oxide forming a mass concentration of $99.1 \%$, is the predominant oxide. However, there are impurities such as sodium, silicon and manganese oxides. The presence of chlorine detected (others), although insignificant in value of concentration, is associated with the pickle with $\mathrm{HCl}$. Other metallic impurities, characterizing the composition of the rust formed during the processing of steel, were detected in very small quantities. Traces of oils and fats were also detected by chemical analysis at a concentration of $3.0 \mathrm{mg} \cdot \mathrm{kg}^{-1}$. The presence of oils and fats

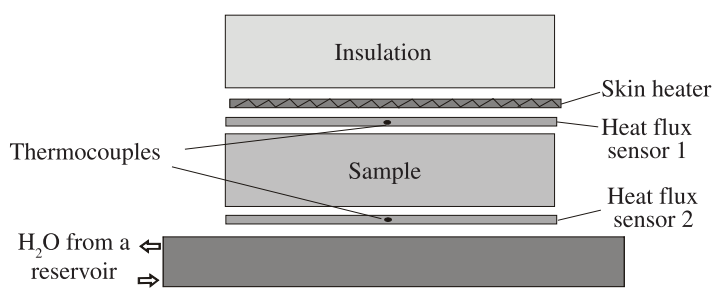

Figure 2. Apparatus used for thermal conductivity measurements.

Table 1. Chemical composition of the used iron oxide residue.

\begin{tabular}{cccccc}
\hline Oxide & $\mathbf{F e}_{2} \mathbf{O}_{3}$ & $\mathbf{N a}_{2} \mathbf{O}$ & $\mathbf{S i O}_{2}$ & $\mathbf{M n O}$ & Others \\
\hline wt. (\%) & 99.1 & 0.216 & 0.208 & 0.207 & 0.269 \\
\hline
\end{tabular}

is due to the treatment of pickling, which, besides having the task of removing iron oxide after the lamination process also eliminates the possible existence of oils and fats. The Table 1 shows, therefore, that the analyzed powder is composed by the oxides identified with a predominance of hematite according to the X-ray diffraction pattern (ICDD, 73-0603) of Figure 3. The theoretical density of the iron oxide under consideration is $5.2 \mathrm{~g} . \mathrm{cm}^{-3}$. However, from the measurements by He-pycnometry the iron oxide waste shows a density value of $4.66 \mathrm{~g} . \mathrm{cm}^{-3}$ which was used for the batch calculations. This difference in density is due to the fact that the iron oxide waste has some impurities in small quantities which decrease the density as shown in Table 1. Table 2 shows the measured and calculated densities of the prepared and produced composites. The calculated density values were obtained by the law of the mixtures by considering density values of 1.05 and $4.66 \mathrm{~g} . \mathrm{cm}^{-3}$ for PU and iron oxide residue, respectively.

As expected the apparent density of the produced composites increased as the iron oxide content increased from 2.5 to $12.5 \% \mathrm{v} / \mathrm{v}$ since iron oxide has a density of

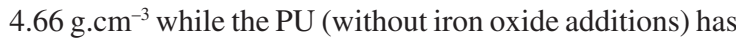


only $1.05 \mathrm{~g} \cdot \mathrm{cm}^{-3}$. Moreover, the measured density values are in good agreement with the calculated one indicating that the batches were well prepared.

The tensile stress of the polyurethane and composites comprising different volume fractions of $\mathrm{Fe}_{2} \mathrm{O}_{3}$ are shown in Figure 4. As it can be seen from the Figure 4 the tensile stress increases with increments of $\mathrm{Fe}_{2} \mathrm{O}_{3}$ volume fraction. For iron oxide addition of $2.5 \% \mathrm{v} / \mathrm{v}$ the tensile stress was similar to the PU, i.e. without addition of the particulate iron oxide. For the composites with 5.0, 7.5, 10 and 12.5\% v/v iron oxide the tensile stress was higher than that of the pure $\mathrm{PU}(\sim 3.2 \mathrm{MPa})$. Thus, in this case, the best result ( 6 MPa)

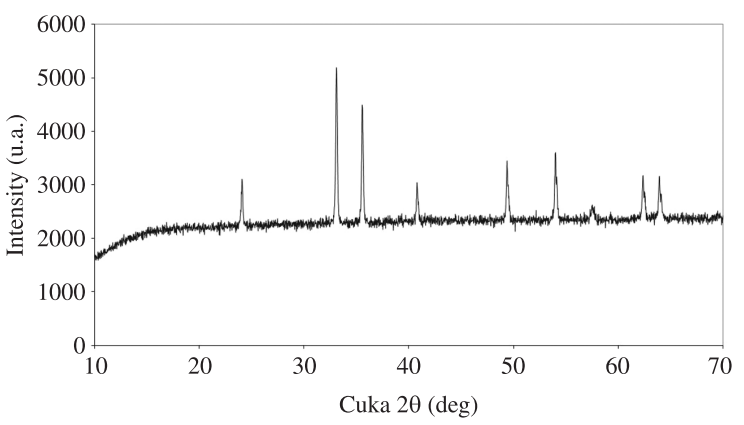

Figure 3. X-ray diffraction pattern of the iron oxide waste.

Table 2. Measured and calculated densities of the composites, PU and iron oxide residue.

\begin{tabular}{ccc}
\hline $\begin{array}{c}\mathbf{P U} / \mathrm{Fe}_{2} \mathbf{O}_{3} \\
\text { composites }(\% \\
\mathbf{v} / \mathbf{v})\end{array}$ & $\begin{array}{c}\text { Measured apparent } \\
\text { density }\left(\mathbf{g . c m}^{-3}\right)\end{array}$ & $\begin{array}{c}\text { Calculated } \\
\text { density }\left(\mathbf{g . c m}^{-3}\right)\end{array}$ \\
\hline $100 / 0$ & $1.05 \pm 0.01$ & - \\
$97.5 / 2.5$ & $1.15 \pm 0.01$ & 1.14 \\
$95 / 05$ & $1.24 \pm 0.04$ & 1.23 \\
$92.5 / 7.5$ & $1.33 \pm 0.09$ & 1.32 \\
$90 / 10$ & $1.41 \pm 0.03$ & 1.41 \\
$87.5 / 12.5$ & $1.49 \pm 0.03$ & 1.44 \\
$0 / 100$ & $4.66 \pm 0.13$ & - \\
\hline
\end{tabular}

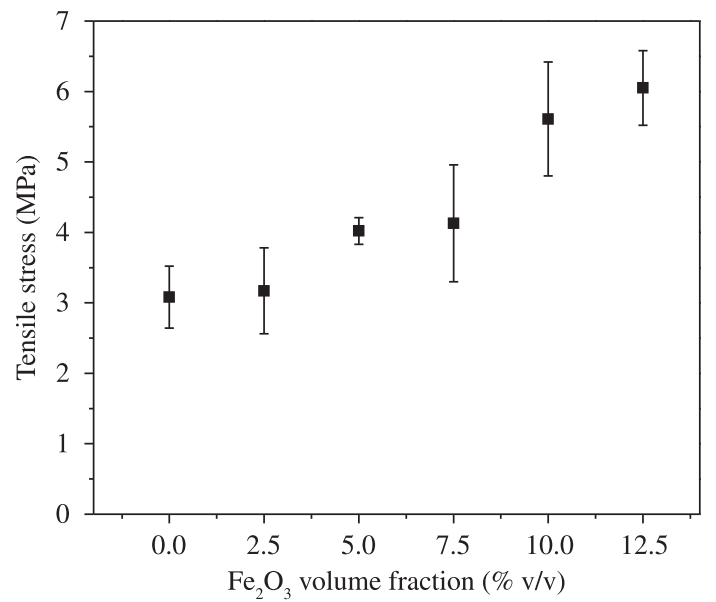

Figure 4. Tensile stress of the PU and PU + iron oxide waste additions. is related to composite containing $12.5 \% \mathrm{v} / \mathrm{v}$ of iron oxide. However, for a volume fraction higher than $12.5 \%$ iron oxide the viscosity increases too much so that the homogenization becomes difficult and forming is not possible. The Young's modulus of the composites with different $\mathrm{Fe}_{2} \mathrm{O}_{3}$ volume content showed similar behavior, increasing for higher volume fractions (Figure 5).

Table 3 shows the results of the measured electrical and thermal properties of the composites used and produced in this work. From Table 3 it can be seen that the electrical conductivity of the compositions (PU + iron oxide) increases with the concentration of the iron oxide going from a value of $3.48 \times 10^{-16}{\mathrm{~S} . \mathrm{cm}^{-1}}$ for the pure PU up to $2.55 \times 10^{-13} \mathrm{~S} . \mathrm{cm}^{-1}$ for $12.5 \%$ of iron oxide in accordance with the measured electrical conductivity value of the iron oxide $\left(9.35 \times 10^{-10}{\left.\mathrm{~S} . \mathrm{cm}^{-1}\right)}^{-}\right.$ which is higher than that of PU and the PU + iron oxide produced composites. Therefore, the electrical conductivity of the pure polymer was increased of 3 orders of magnitude. Proportionally, there is a decrease in resistivity i.e. from $2.87 \times 10^{15} \Omega$.cm for pure PU to a value of $3.92 \times 10^{12} \Omega . \mathrm{cm}$ for composition containing $12.5 \%$ of iron oxide.

From analysis of the obtained data it can observe that the electrical conductivity values do not vary significantly. Nevertheless, the addition of iron oxide does not change the insulation behavior of the PU, making it stay in the range of conductivity of a typical electrical insulator (between $10^{-10}$ and $10^{-20}{\mathrm{~S} . \mathrm{cm}^{-1}}^{19}$.

The thermal conductivity for the vast majority of polymers is of order of $0.30 \mathrm{~W} / \mathrm{mK}^{21}$ but for polyurethane resins it corresponds to $0.209 \mathrm{~W} \cdot \mathrm{mK}^{-1[20]}$. The iron oxide has a relatively high thermal conductivity compared to the polymer materials, i.e., $20 \mathrm{~W} \cdot \mathrm{mK}^{-1[11]}$, but remains in the range of conductivity characteristics of ceramics (at room temperature ranged between 2 and $\left.50 \mathrm{~W} \cdot \mathrm{mK}^{-1}\right)^{21}$. From analysis of thermal properties of the pure polyurethane and various composites it can be seen that the iron oxide additions do not significantly change the value of thermal conductivity.

The thermal conductivity of the studied compositions remains rather low because the volume fraction of the iron oxide added is not high (the maximum is $12.5 \%$ ). It is also

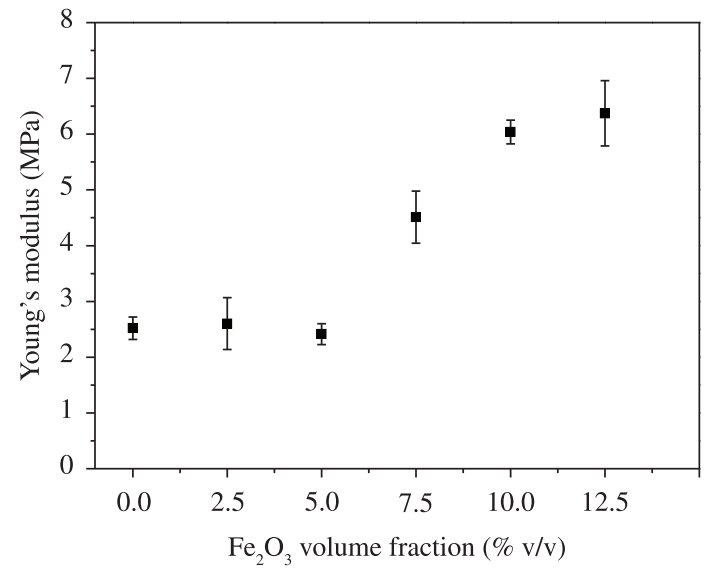

Figure 5. Young's modulus of the PU and composites with different $\mathrm{Fe}_{2} \mathrm{O}_{3}$ volume content. 
Table 3. Measured electrical and thermal properties of the composites, PU and iron oxide residue.

\begin{tabular}{cccc}
\hline $\begin{array}{c}\mathbf{P U}_{\mathbf{F e}} \mathbf{O}_{\mathbf{3}} \text { composites } \\
(\mathbf{\%} \text { v/v })\end{array}$ & $\begin{array}{c}\text { Electrical resistivity } \\
(\Omega . \mathbf{c m})\end{array}$ & $\begin{array}{c}\text { Electrical conductivity } \\
\left(\mathbf{S . c m}^{-1}\right)\end{array}$ & $\begin{array}{c}\text { Thermal conductivity } \\
(\mathbf{W . m K})\end{array}$ \\
\hline $100 / 0$ & $(2.87 \pm 0.02) \times 10^{15}$ & $(3.48 \pm 0.01) \times 10^{-16}$ & $0.191 \pm 0.03$ \\
$97.5 / 2.5$ & $(1.38 \pm 0.13) \times 10^{15}$ & $(7.26 \pm 0.12) \times 10^{-16}$ & $0.233 \pm 0.04$ \\
$95 / 05$ & $(1.45 \pm 0.17) \times 10^{14}$ & $(6.90 \pm 0.15) \times 10^{-15}$ & $0.268 \pm 0.01$ \\
$92.5 / 7.5$ & $(1.03 \pm 012) \times 10^{14}$ & $(9.73 \pm 0.14) \times 10^{-15}$ & $0.290 \pm 0.02$ \\
$90 / 10$ & $(1.35 \pm 0.09) \times 10^{13}$ & $(7.40 \pm 0.11) \times 10^{-14}$ & $0.320 \pm 0.03$ \\
$87.5 / 12.5$ & $(3.92 \pm 0.07) \times 10^{12}$ & $(2.55 \pm 0.06) \times 10^{-13}$ & $0.340 \pm 0.01$ \\
$0 / 100$ & $(1.07 \pm 0.16) \times 10^{9}$ & $(9.35 \pm 0.19) \times 10^{-10}$ & - \\
\hline
\end{tabular}

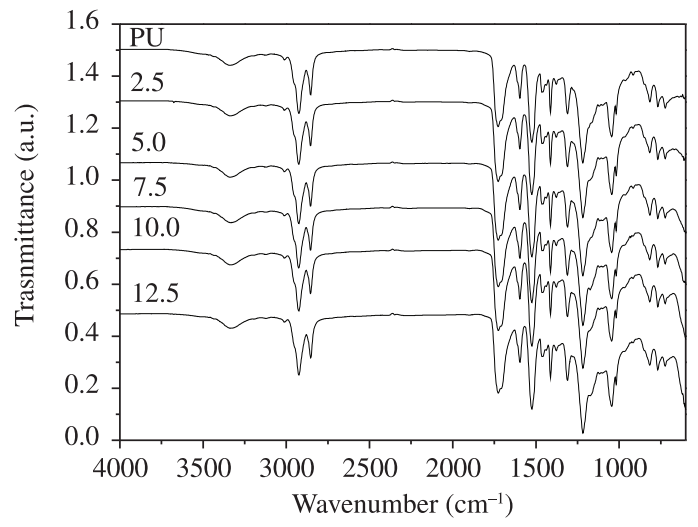

Figure 6. ATR-FTIR spectrum of PU and composites with 2.5, 5.0, $7.5,10$ and $12.5 \%$ of iron oxide.

worth noting that the pure iron oxide has a high thermal resistance. This means that even with the $12.5 \%$ iron oxide the composite as well as the pure polyurethane are classified as thermal insulators. It may be noted that, generally, by increasing the iron oxide amount the internal conductivity of the material also increases, ranging from $0.191 \mathrm{~W} . \mathrm{mK}^{-1}$ for PU up to $0.340 \mathrm{~W} \cdot \mathrm{mK}^{-1}$ for PU enriched with $12.5 \% \mathrm{v} / \mathrm{v}$ of iron oxide.

The Figure 6 shows infrared spectra of the pure PU and composites with different $\mathrm{Fe}_{2} \mathrm{O}_{3}$ volume fraction. The spectrum for the unreinforced polyurethane derived from castor oil shows absorption bands assigned to amine $\left(3330 \mathrm{~cm}^{-1}\right)$, methyl $\left(2927 \mathrm{~cm}^{-1}\right)$ and methylene $\left(2853 \mathrm{~cm}^{-1}\right)$ groups. The absorption band due to the carbonyl stretching vibration (amide I band) of the urethane pre-polymer occurred at around $1726 \mathrm{~cm}^{-1}$. The combination of $\mathrm{NH}$ deformation and $\mathrm{CN}$ stretching vibration (amide II bands)

\section{References}

1. Silva RV. Compósito de resina poliuretana derivada do óleo de mamona e fibras vegetais. [Tese]. São Carlos: Universidade de São Paulo; 2003.

2. Monteavaro LL. Poliuretanas a partir de polióis de óleo de soja. [Tese]. Porto Alegre: Universidade Federal do Rio Grande do Sul; 2005.

3. Mohanty AK, Misra M and Drzal LT. Natural fibers, biopolymers, and biocomposites. Boca Raton: Taylor \& Francis; 2005. p. 845. http://dx.doi.org/10.1201/9780203508206 occurred at $1521 \mathrm{~cm}^{-1}$. The absorption bands at 1216 and $1047 \mathrm{~cm}^{-1}$ are assigned to ether groups ${ }^{22}$. The composites IR spectrum shows the same absorption bands, indicating that have not interactions between matrix and iron oxide particles. Thus, the oxide particles remain fairly isolated in the matrix not allowing an interaction between them, according to low values of thermal conductivity.

\section{Conclusions}

The results presented in this study showed that the residue has $99.1 \%$ of iron oxide (hematite, $\alpha-\mathrm{Fe}_{2} \mathrm{O}_{3}$ ) and can be effectively used as filler in polymer composites. Due to the higher density of the iron oxide, the apparent density of the composites increases proportionally to the content of the iron oxide residue. Tensile stress and Young's modulus slightly increases for higher volume fractions, indicating that the residue can be used effectively as filler agent in a polyurethane matrix derived from castor oil, in different industrial sectors, such as the furniture industry, automotive, footwear, among others. The thermal and electrical properties were not significantly affected by addition of iron oxide residue, and did not cause changes in the insulating characteristics of the PU matrix. It was not observed chemical interaction between polyurethane and iron oxide. The results obtained in this study demonstrated that iron oxide residue can be used as efficient filler in a polyurethane matrix derived from castor oil, in a range of new and existing applications, as for example in internal automotive components.

\section{Acknowledgements}

The authors are grateful to Capes and $\mathrm{CNPq} / \mathrm{Brazil}$ for funding this work.

4. Liu G, Li L and Yang X. Preparation of ellipsoidal hematite/ polymer hybrid materials and the corresponding hallow polymer ellipsoids. Polymer. 2008; 49:4776-4783. http:// dx.doi.org/10.1016/j.polymer.2008.08.043

5. Chen J, Xu L, Li W and Gou X. $\alpha-\mathrm{Fe}_{2} \mathrm{O}_{3}$ Nanotubes in Gas Sensor and Lithium-Ion Battery Applications. Advanced Materials. 2005; 17:582. http://dx.doi.org/10.1002/ adma.200401101

6. Gondal MA, Hameed A, Yamani ZH and Al-Suwaiyan A. Laser Induced Photocatalytic Oxidation of Water: Activity 
Comparison of $\alpha-\mathrm{Fe}_{2} \mathrm{O}_{3}, \mathrm{WO}_{3}, \mathrm{TiO}_{2}$ and $\mathrm{NiO}$ Catalysts. Chemical Physics Letters. 2004; 385:111. http://dx.doi. org/10.1016/j.cplett.2003.12.066

7. Jiang JZ, Lin R, Lin W, Nielsen K, Morup S, Dam-Johansen $\mathrm{K}$ et al. Gas-sensitive properties and structure of nanostructured $\left(\left(\alpha-\mathrm{Fe}_{2} \mathrm{O}_{3}\right)_{x}-\left(\mathrm{SnO}_{2}\right)_{\mathrm{L}-x}\right.$ materials prepared by mechanical alloying. Journal of Physics D: Applied Physics 1997; 30:1459. http://dx.doi.org/10.1088/0022-3727/30/10/012

8. Prim SR, Folgueras MV, Lima MA and Hotza D. Synthesis and characterization of hematite pigment obtained from a steel waste industry. Journal of Hazardous Materials. 2011; 192:1307-1313. PMid:21803495. http:// dx.doi.org/10.1016/j.jhazmat.2011.06.034

9. Instituto Brasileiro de Siderurgia - IBS. Report of 2010. Available from: <www.acobrasil.org.br>. Access in: 16/02/11.

10. Merlini C, Soldi V and Barra GMO. Influence of fiber surface treatment and length on physico-chemical properties of short random banana fiber-reinforced castor oil polyurethane composites. Polymer Testing. 2011; 30:833-840. http://dx.doi. org/10.1016/j.polymertesting.2011.08.008

11. American Society for Testing and Materials -ASTM. D638-08: Standard Test Method for Tensile Properties of Plastics. ASTM; 2008.

12. American Society for Testing and Materials - ASTM. D3039M-08: Standard Test Method for Tensile Properties of Polymer Matrix Composite Materials. ASTM; 2008.

13. American Society for Testing and Materials - ASTM. D257-99: Standard Test Methods for DC Resistance or Conductance of Insulating Materials. ASTM; 1999.
14. Girotto EM and Santos IA. Medidas de Resistividade Elétrica DC em Sólidos: Como Efetuá-las Corretamente. Química Nova. 2002; 25(4).

15. Guths S. Heat Flux Sensors. In: Orlande H, Fudym O, Maillet $\mathrm{D}$, Cotta RM, organizers. Thermal Measurements and Inverse Techniques. Boca Raton: CRC Press; 2011. v. 1, p. 171-184.

16. Guths S, Philippi PC, Gaviot E and Thery P. A flowmeter by tangential gradient transducer. Brazilian Congress of Mechanical Engineering - COBEM; 1995. p.172-183.

17. International Organization for Standardization - ISO. ISO 8301:1991: Thermal insulation - Determination of steady-state thermal resistance and related properties - Heat flow meter apparatus. ISO; 1991.

18. American Society for Testing and Materials-ASTM. C518-10: Standard Test Method for Steady-State Thermal Transmission Properties by Means of the Heat Flow Meter Apparatus. ASTM; 2010.

19. American Society for Testing and Materials - ASTM. C518-1991: Standard Test Method of Steady - State Heat Flux Mesurements and Thermal Transmission Properties by Means of the Heat Flow Meter Apparatus. ASTM; 1991.

20. Callister Junior WD. Materials Science and Engineering - An Introduction. 4th ed. New York: Willey; 1996.

21. Rabello MS. Aditivos de Polímeros. São Paulo: Editora Artliber; 2000.

22. Sinha $E$ and Rout SK. Influence of fibre-surface treatment on structural, thermal and mechanical properties of jute. Journal of Materials Science. 2008; 43:2590-2601. http://dx.doi. org/10.1007/s10853-008-2478-4 